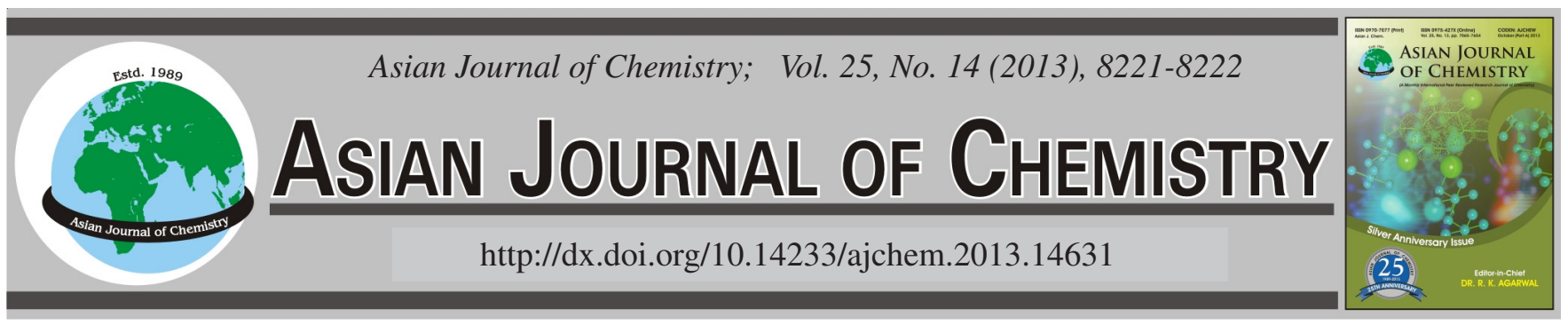

NOTE

\title{
Synthesis and Crystal Structure of a Novel Square-Hole-Shaped Molecule Mercury(II): $\mathrm{C}_{50} \mathrm{H}_{48} \mathrm{Hg}_{2} \mathrm{~N}_{2} \mathrm{O}_{10} \mathrm{~S}_{4}$
}

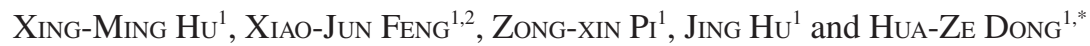

${ }^{1}$ Department of Chemistry and Chemical Engineering, Hefei Normal University, Hefei 230061, P.R. China

${ }^{2}$ Food and drug department, Qingyuan Polytechnic, Qingyuan 511510, P.R. China

*Corresponding author: E-mail: xiaoche7207@126.com; dapdong@163.com

\begin{abstract}
A novel complex $\left(\mathrm{C}_{50} \mathrm{H}_{48} \mathrm{~N}_{2} \mathrm{O}_{10} \mathrm{~S}_{4} \mathrm{Hg}_{2}\right)$ was synthesized by pyridyl-pyrimidine dithioethers and $\mathrm{Hg}(\mathrm{OAc})_{2}$ in $\mathrm{CH}_{3} \mathrm{OH}$. As the square-holeshaped molecule, the title compound shows five-coordinate core $\left(\mathrm{HgO}_{3} \mathrm{~N}_{1} \mathrm{~S}_{1}\right)$ which is distorted dipyramid geometry. The crystal is trioclinic, space group P-1 with unit cell parameters: $\mathrm{a}=10.10(6) \AA, \mathrm{b}=11.14(5) \AA, \mathrm{c}=13.41(6) \AA, \mathrm{a}=106.3(4)^{\circ}, \beta=103.3(4)^{\circ}, \gamma=99.4(4)^{\circ}, \mathrm{V}=$ $1367(13) \AA^{3}, Z=1, M r=1506.46, D c=1.830 \mathrm{~g} / \mathrm{cm}^{3}, \mu=5.830 \mathrm{~mm}^{-1}, \mathrm{~F}(000)=736, \mathrm{R}=0.0592, \mathrm{wR}=0.1403$ for 6870 reflections with $\mathrm{I}>2 \sigma(\mathrm{I})$

Key Words: Pyridyl-pyrimidine dithioether, van der Waals forces.
\end{abstract}

Two kinds of compounds were prepared in our earlier report $^{1}$, in which, as ligand, pyridyl-pyrimidine dithioether displayed different frameworks with different mercuric(II) salt for anions. With in-depth study, a novel square-hole-shaped macromolecular mercury(II) complex has been synthesized, whose crystal structure has emerged through elemental analysis and X-ray diffraction analysis.

All reagents were of analytical grade and were used without further purification. Analyses for carbon, hydrogen and nitrogen were performed on a Perkin-Elmer $140{ }^{\circ} \mathrm{C}$ analyzer. Infrared spectra (4000-400 $\mathrm{cm}^{-1}$ ) were recorded with a Bruker Vector 22 FT-IR spectrophotometer on $\mathrm{KBr}$ disks.

Synthesis: The ligand (L) was synthesized with 1,3dibromopropane and 4-(pyridin-4-yl)pyrimidine-2-thiol according to literatures ${ }^{2-5}$, which then reacted with $\mathrm{Hg}(\mathrm{OAc})_{2}$ in $\mathrm{CH}_{3} \mathrm{OH}$. The mixture was refluxed for $0.5 \mathrm{~h}$ and then cooled to room temperature. The solution was filtered, then title complex was obtained by slow evaporation of the filtrate at room temperature in $70 \%$ yield, whose structure has been determined by X-raycrystallography. The formula of crystals is $\mathrm{C}_{50} \mathrm{H}_{48} \mathrm{~N}_{2} \mathrm{O}_{10} \mathrm{~S}_{4} \mathrm{Hg}_{2}(\mathbf{1})$ of which structure is showed in Fig. 1.

Anal. calcd. for $\mathrm{C}_{50} \mathrm{H}_{48} \mathrm{~N}_{2} \mathrm{O}_{10} \mathrm{~S}_{4} \mathrm{Hg}_{2}$ : C: 43.95; H: 3.54; N: $2.05 \%$. Found: C: 43.92; H: 3.54; N: $2.06 \%$. IR (KBr, $v_{\max }$, $\left.\mathrm{cm}^{-1}\right)$ : 3432 (m), 1593 (w), 1562 (s), 1541 (m), 1480 (w), 1401 (m), 1382 (s), 1351 (m), 1322 (m), 1203 (m), 1026 (w), $831(\mathrm{w})$.

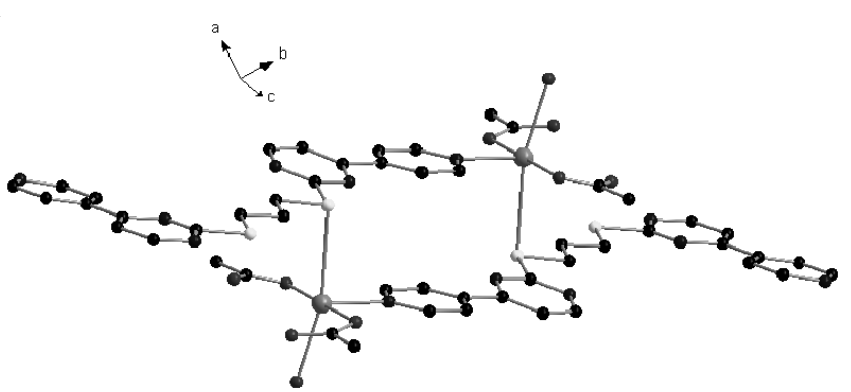

Fig. 1. Molecular structure of the mercury complex

Crystal structure determination: A single crystal of compound with dimensions of $0.08 \mathrm{~mm} \times 0.20 \mathrm{~mm} \times 0.40$ $\mathrm{mm}$ was selected for the crystallographic data collection at 291(2)K and structure determination on a Bruker SMART CCD-4 K diffractometer employing graphite-monochromated $\mathrm{MoK}_{\alpha}$ radiation $(\lambda=0.71073 \AA$ ). A total of 6870 reflections were collected in the range of $1.65^{\circ} \leq \theta \leq 25.0^{\circ}$, of which 4738 reflections were unique with $\mathrm{R}_{\text {int }}=0.093$. The data were collected using SMART and reduced by the program SAINT. All the structures were solved by direct methods and refined by full-matrix least squares method on $\mathrm{F}^{2}$ obs by using SHELXTL-PC software package. Non-hydrogen atoms were placed in geometrically calculated positions. Hydrogen atoms were added according to theoretical model. The final full- 
TABLE-2

INTRAMOLECULAR HYDROGEN BOND DISTANCES $(\AA)$ AND ANGLES $\left({ }^{\circ}\right)$

\begin{tabular}{|c|c|c|c|c|c|}
\hline 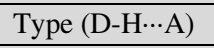 & $\mathrm{d}(\mathrm{D}-\mathrm{H})$ & $\mathrm{d}(\mathrm{H} \cdots \mathrm{A})$ & $\angle(\mathrm{DHA})$ & $\mathrm{d}(\mathrm{D} \cdots \mathrm{A})$ & A \\
\hline C9--H9·-N6 & 0.9300 & 2.5800 & 134.00 & $3.29(3)$ & $\mathrm{x},-1+\mathrm{y},-1+\mathrm{z}$ \\
\hline C10--H10A.·O2 & 0.9700 & 2.5100 & 148.00 & $3.37(3)$ & $1-x,-y, 1-z$ \\
\hline C16--H16..O5 & 0.9300 & 2.5300 & 122.00 & $3.12(2)$ & $1-x,-y, 2-z$ \\
\hline
\end{tabular}

matrix least-squares refinement including 354 variable parameters for 3395 reflections with $\mathrm{I}>2 \sigma(\mathrm{I})$ and converged with unweighted and weighted agreement factors of:

$$
\mathrm{R}_{1}=\Sigma\left(|| \mathrm{F}_{0}|-| \mathrm{F}_{\mathrm{c}} \|\right) / \Sigma\left|\mathrm{F}_{0}\right|=0.0592
$$

and

$$
\mathrm{wR}_{2}=\left\{\Sigma\left[\mathrm{w}\left(\mathrm{F}_{0}^{2}-\mathrm{F}_{\mathrm{C}}^{2}\right)^{2}\right] / \Sigma \mathrm{w}\left(\mathrm{F}_{0}^{2}\right)^{2}\right\}^{1 / 2}=0.1403
$$

where $\mathrm{w}=1 /\left[\sigma^{2}\left(\mathrm{~F}_{0}^{2}\right)+(0.0584 \mathrm{P})^{2}\right]$ and $\mathrm{P}=\left(\mathrm{F}_{0}{ }^{2}+2 \mathrm{~F}_{\mathrm{C}}{ }^{2}\right) / 3$. The maximum and minimum peaks on the final difference Fourier map are corresponding to 1.63 and $-1.17 \mathrm{e} / \AA^{3}$, respectively.

The parameters of selected bonds and hydrogen bonds are shown in Tables 1 and 2 correspondingly. The molecular structure and packing diagram of the compound are shown in Figs. 1 and 2, respectively. The title compound crystallizes in the triclinic system of $\mathrm{P}-1$ space group. The shape of complex is square-hole shaped. In $\mathrm{HgO}_{3} \mathrm{~N}_{1} \mathrm{~S}_{1}$ core, $\mathrm{Hg}$ atom is coordinated by three $\mathrm{O}$ atoms and one $\mathrm{N}$ atom as well as one $\mathrm{S}$ atom in a distorted triangular dipyramid geometry, in which the two $\mathrm{O}$ atoms $(\mathrm{O} 1, \mathrm{O} 3)$ are from different acetate anion and one $\mathrm{O}$ atom is from coordinated water molecule, the $\mathrm{N}$ atom and $\mathrm{S}$ atom are from distinct ligands. The axial bond angle (O5-Hg1$\mathrm{S} 1 \mathrm{a})$ is $165.8(4)^{\circ}$. The bond length $\left(\mathrm{Hg} 1-\mathrm{S} 1 \_\mathrm{a}\right)$ is $3.068(19)$ $\AA$ that is similarly longer with named classical coordination bond. In addition, the two $\mathrm{Hg}-\mathrm{O}$ bond lengths (Hg-O1 and $\mathrm{Hg}-\mathrm{O} 3$ ) are not same. The pyrimidyl and pyridyl unit in the middle of chelate ring of the complex are planar for intermolecular hydrogen bonds respectively. The chelate ring shows a square-hole because non-axial bond angles around $\mathrm{Hg}$ (II) are about $90^{\circ}$.

TABLE-1 SELECTED BOND DISTANCES $(\AA)$ AND ANGLES $\left({ }^{\circ}\right)$

\begin{tabular}{cccc}
\hline Hg1-O1 & $2.253(17)$ & S1_a-Hg1-O1 & $87.5(5)$ \\
Hg1-O3 & $2.184(17)$ & S1_a-Hg1-O3 & $91.4(5)$ \\
Hg1-O5 & $2.529(17)$ & S1_a-Hg1-N3 & $92.4(5)$ \\
Hg1-N3 & $2.356(16)$ & Hg1_a-S1-C1 & $99.4(6)$ \\
Hg1-S1_a & $3.068(19)$ & Hg1_a-S1-C10 & $98.5(6)$ \\
\hline
\end{tabular}

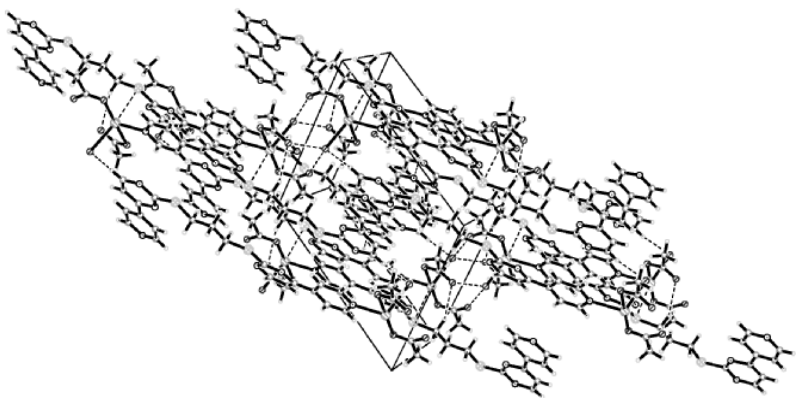

Fig. 2. Packing diagram of the title compound via van der Waals forces

\section{Conclusion}

With transforming the distance of two sulfur atom and the substitutional position of nitrogen in ligand, which is pyridyl-pyrimidin dithioether, the new mercuric(II) complex is still macrocycle, but the cycle is made of two central ions and two part of ligand-moleculars.

Supplementary material: Crystallographic data for the structure reported in this communication have been deposited with the Cambridge crystallographic data center as supplementary publication No. CCDC 760047.

\section{ACKNOWLEDGEMENTS}

The authors are indebted to the National Natural Science Foundation of China (No. 211101053,No. 20871039) for financial support. This work is also supported by the Anhui Provincial Science Research Projects (KJ2011Z301, KJ2011Z306).

\section{REFERENCES}

1. H.Z. Dong, J. Yang, X. Liu and S.H. Gou, Inorg. Chem., 47, 2913 (2008).

2. J.P. Zhang and X.M. Chen, Chem. Commun., 1689 (2006)

3. X.M. Zhang, Coord. Chem. Rev., 249, 1201 (2005).

4. H.Z. Dong, J. Zhao, S.H. Gou and H.B. Zhu, Polyhedron, 28, 1040 (2009).

5. H.Z. Dong, W.T. Bi and H.B. Zhu, Asian J. Chem., 21, 5607 (2009). 